Proceedings

\title{
Trends in CITES Listed Bird's Trade in South Asian Countries in View of Evolution of Indian Laws during Last Four Decades
}

$+$

\author{
Asha Poonia ${ }^{1 *}$, Monika Jangra ${ }^{1}$, Anil Ghanghas ${ }^{2}$, Virender Sindhu ${ }^{3}$ and Radhika Sharma ${ }^{4}$
}

1- Faculty of Life Sciences, Chaudhary Bansi Lal University, India

2- Faculty of Law, Chaudhary Devi Lal University, India

3- Faculty of Law, Mahrishi Dayanad University, Rohtak

4- College of Basic Sciences, CSKHPKV, Palampur

* Correspondence: author Email address- asha.poonia@cblu.ac.in, asha.poonia@gmail.com

+ Presented at the 1st International Electronic Conference on Biological Diversity, Ecology, and Evolution, 1531 March 2021.

\begin{abstract}
Wildlife is considered to be a very effective money making trade. Very lucrative and important among these is trade in cage birds. It is considered to be difficult to obtain information on both legal and illegal aspects of trade. Present study is an attempt to understand the changing trade of Convention on International Trade in Endangered Species of Wild Fauna and Flora (CITES) enlisted bird species of South Asian countries with focus on India-relating to ever emerging wildlife laws in India. This study has taken into account CITES listed bird's import and export since 1975 to 2019 for India, Pakistan, Bangladesh and Nepal. The analysis has showed that import as well as export of birds in India has rapidly declined after 1991, which may be associated with The Wildlife Protection (Amendment) Act, 1991. The analysis also shows that import of birds has started rising for Nepal, Bangladesh and Pakistan since 1991 and has increased tremendously from 2010 for Bangladesh and Pakistan. Maximum of these birds are captive birds. These birds may end up in India from its porous border with adjoining countries. The authors suggest reading between the lines and having an improved system of surveillance for illegal bird trade.
\end{abstract}

Keywords: CITES; import; export; bird trade; Psittaciformes; Passeriformes; parrot trade; India; The Wildlife Protection Act; Pakistan; Nepal; South Asia; Bangladesh 